\title{
LAZER E TURISMO PARA O DESENVOLVIMENTO NA ESCALA HUMANA
}

\author{
Luzia Neide Coriolano \\ Universidade Estadual do Ceará, Brasil
}

\begin{abstract}
Resumo: O lazer e o turismo assumem importância no mundo contemporâneo e estão relacionados ao desenvolvimento não apenas enquanto geradores de oportunidades no mundo do trabalho, mas também como dimensão indicativa da qualidade de vida das pessoas. A expansão dos serviços enseja a realização de estudos que promovam a teorização do setor o que leva ao debate sobre desenvolvimento. Nesta perspectiva, considerando que são atribuídos diferentes significados à palavra desenvolvimento apresentase breve revisão crítica sobre o tema, desde o entendimento como sinônimo de crescimento, às ideias a partir dos anos 1970 quando se avança no concepção de que desenvolvimento diz respeito às pessoas e não às coisas. Questionam-se concepções de desenvolvimento e o modelo de desenvolvimento hegemônico e, portanto o modelo de turismo hegemônico. Relaciona-se o turismo ao modelo de desenvolvimento no qual é projetado daí identifica-se a necessidade de se repensar o turismo gerando outras formas de desenvolvêlo para além do modelo hegemônico. Enfatiza-se o desenvolvimento local e na escala humana. Com os resultados do estudo aprofunda-se a análise elencando possibilidades e iniciativas de desenvolvimento na escala humana por meio do turismo..
\end{abstract}

Palavras-chave: lazer; turismo; desenvolvimento local; desenvolvimento na escala humana.

\section{Introdução}

Este texto é um convite à revisão do modelo de desenvolvimento hegemônico, mais que isto, uma crítica, a fim de que se possa pensar uma revolução no modo de viver, de produzir e de fazer lazer e turismo. Pois o que se deseja é uma sociedade justa, sustentável, com o lazer contribuindo com a elevação da qualidade de vida dos residentes e a satisfação dos turistas, longe do puro consumismo. Isto requer pensar lazer e turismo como atividade solidária de aprendizagem entre povos e culturas, além da oportunidade de negócios, em municípios e comunidades, como uma atividade que promova o desenvolvimento local, mesmo realizando seu objetivo original, para o qual foi planejado, de promover acumulação de capital na esfera global.

O lazer, expressão e manifestação da sociedade contemporânea, em forma de turismo, esporte, arte, dança, folclore, festa e show, ocupa cada vez mais centralidade no mundo contemporâneo, contrapondo-se ao que movimenta a sociedade industrial - o trabalho. Mudanças de concepções, de visões de sociedade e mudanças no trabalho impõem transformações à sociedade e ao capitalismo, que se torna parasitário ao tempo de fazer 
surgir contrapontos e esperanças de variações (BAUMAN, 2010). O trabalho é paradigma da sociedade industrial e seu oposto - o lazer - passa a ser protótipo da sociedade flexível. Na medida em que o trabalho faz-se precário e o desemprego aumenta, a economia hegemônica produz experiências comunitárias alternativas de economia solidária e de comunhão, em contrapontos. O lazer e o turismo globalizados, da sociedade industrial, transformados em mercadorias, são enfrentados com formas diferenciadas de ócio ou uso de tempo para entrega a si mesmo, recreação, sonho, criação de outros lazeres e turismo, diferenciadamente, por ser de forma comunitária.

O lazer e o turismo enquadram-se no setor dos serviços modernos que representa forma de reestruturação da crise industrial. Os serviços são atividades funcionais às produções industriais e servem de suporte à recuperação do trabalho humano, ao progressivo crescimento das relações industriais, comerciais e financeiras dos diversos mercados internacionais. Hotéis, restaurantes, agências de viagens, comunicações, ambientes para lazer, equipamentos turísticos sustentam a mobilidade da mão de obra globalizada, ou seja, indiretamente, serve de estratégia à reprodução do capital. Tais serviços são muitas vezes subestimados e pouco explicados conforme afirma Chesnais (1996, p. 187):

Falta uma base teórica para explicar o lugar dos serviços e de seu modo de acumulação no capitalismo contemporâneo. O conceito de serviço é definido pelo mais pobre dos métodos: o residual, ou seja, toda atividade que não pode ser classificada no setor manufatureiro, nem no setor agrícola fica pertencendo ao terciário.

Os investimentos industriais em pesquisa e em desenvolvimento, (P\&D), informática e tecnologias estão entre as despesas industriais mais concentradas do mundo. Torna-se importante explicar o atual lugar dos serviços na acumulação, assim como, a contribuição do comércio, da multimídia, das telecomunicações, do lazer e turismo, por exemplo. Estudar, portanto, o lazer e o turismo compreendendo a importância na acumulação e a vinculação às políticas imobiliária, financeira, de urbanização e comércio. Dentre outras relações é uma oportunidade para se entender o mundo e a sociedade contemporâneos e, sobretudo, para propor políticas de ócio e lazer. Grande parte dos serviços é oligopolista, com mercado em que a oferta é controlada por um pequeno grupo. A competição tem por base não somente os preços, mas a propaganda e qualidade do produto, contribuindo para alta concentração de capital. As multinacionais prestadoras de serviços encontram formas e combinações de investimentos nas modalidades de acordo, cooperação e parceria. A aquisição-fusão é o 
processo mais comum dos serviços, sejam os do lazer, turismo, bancários, seguros, telecomunicação, transportes rodoviários e aéreos.

Em torno de algumas atividades industriais mais dinâmicas e geradoras de maior acumulação, organizam-se vários serviços e grupos empresariais. No turismo, organizam-se em formas de conglomerados entre grandes e pequenas empresas, por exemplo, as grandes cadeias de hotéis, restaurantes, e de transportes para as viagens disponibilizam franquias e contratos de gestão para aumentar sua acumulação com o trabalho de pequenas empresas na cadeia produtiva. $\mathrm{Na}$ locação de automóveis ocorrem franquias e acordos com transportadoras; no trabalho temporário, na consultoria financeira e fiscal, a modalidade mais evidente é a filiação de escritórios à rede de escritórios internacional. As multinacionais em serviços desenvolvem formas e combinações de investimentos inovadoras, mas às vezes resgatam modalidades passadas.

O setor de serviço emprega mais do que a indústria, embora com menor salário e o lazer é um dos que mais oferece oportunidade de trabalho. As corporações globais são capazes de produzir um volume de bens e serviços com uso de trabalho cada vez em menor quantidade. Esse é um fato incontestável, contudo tal tendência não acontece em todos os locais ou setores, pois são criadas formas alternativas de trabalhar e de produzir que absorvem mais trabalhadores. A cada dia há informações diversas sobre trabalhos alternativos em diferentes lugares do País.

O turismo de base local, por exemplo, é aquele realizado para atender as necessidades dos moradores de um lugar, sem visar apenas o lucro - faz contraponto ao modelo de desenvolvimento hegemônico e contraditório. Esse modelo hegemônico de desenvolvimento se faz pela exploração dos territórios, sobretudo no turismo, pois é considerado um dos serviços especiais, ao se tornar eficiente, eficaz, e atender às necessidades do capital. O turismo passa a fazer parte da missão de várias empresas estatais e privadas.

Desenvolvimento é um conceito associado à ideia de fazer as nações pobres caminharem em busca da superação de suas pobrezas, o que tem levado todos a irem a essa busca, e às vezes, equivocadamente. O discurso do desenvolvimento compõe-se de uma rede de conceitos chave tais como riqueza-pobreza, produção-consumo, Estadosociedade, igualdade-desigualdade, políticas público-privadas que precisam ser analisados para se compreender o modelo de sociedade atual e o que se pode fazer para transformá-la. Desenvolvimento é um conceito construído pelos países dominantes que desejavam "explicar as desigualdades" entre os países sem entrar no mérito da questão, 
apenas responsabilizando-os por sua situação desvantajosa em relação aos países centrais do capitalismo. Isto é, foi um conceito associado à ideologia de que as nações pobres podem superar tais problemas, caso caminhem conforme as regras estabelecidas pelos países dominantes. Essa ideia permeia as políticas nacionais de quase todos os países, desde a Segunda Guerra Mundial, mesmo entre aqueles que iniciaram processo de descolonização.

Ao desenvolvimento atribui-se significados, valorações e direções, associado a algo positivo ou que conduz para melhor. Quase sempre falar de desenvolvimento é falar do futuro, do mundo que se quer (do devir) e não do mundo que se vive. Desenvolvimento é um processo multidimensional, territorial, ambiental, econômico, social e cultural. Uma forma de percepção que tem modelado a realidade, produzindo mitos, fantasias, paixões, violências, e políticas. Portanto, para tratar da realidade é preciso deixar explícitos os elementos e os nexos principais que conduzem a lógica do desenvolvimento hegemônico e qual desenvolvimento se pretende alcançar, desde que fuja do proposto pela economia clássica e reduzido ao crescimento econômico.

Durante muito tempo pensou-se que o crescimento econômico fosse o próprio desenvolvimento. Hoje, há consenso mundial da diferença entre crescimento e desenvolvimento, embora se possa admitir alguma relação entre eles. No Brasil, vários críticos (professores, pesquisadores, técnicos e políticos) admitem que, desde os anos 1970, houve crescimento econômico, mas não desenvolvimento, sobretudo em algumas regiões e lugares. Para alcançar o desenvolvimento faz-se necessário que o lugar passe por um processo de produção de riqueza com partilha e distribuição social, considerando os princípios de equidade, as necessidades das pessoas, com justiça social ou direitos humanos.

Pensar o desenvolvimento exige outra lógica, que não a da produtividade a qualquer custo, competitividade e acumulação, encerra uma revolução de ideias e práticas sociais, que oriente pessoas e organizações para a produção e o consumo partilhado, respeitando os ciclos da natureza. Nesta perspectiva, praticamente inverte-se a ordem clássica, a economia colocando-se em função do desenvolvimento para que passe a estar centrado no ser humano, e não na acumulação do capital. Quando se diz que um país é desenvolvido, não significa dizer que concluiu o processo, ao contrário, continua desenvolvendo, não estacionou, nem deixou de crescer, de produzir e de distribuir. A ideia desenvolvimentista transmite a experiência dos países ricos com a intenção de universalizá-la, porém o discurso nem sempre se concretiza na prática. 
O desenvolvimento orientado pelo modelo dos Estados Unidos, utilizando órgãos de desenvolvimento, foi alvo de diversas críticas, pois os resultados ficam limitados a poucos. O modo de produção capitalista reproduziu-se no mundo em termos da concentração e da centralização setorial, espacial e em classes sociais. Tal lógica concentradora e centralizadora provocou desgastes violentos ao planeta, não sendo, portanto "farol", nem modelo que se preze. E finalmente quando o modelo de "desenvolvimento hegemônico" - qual seja o capitalismo agressivo - revelou sua face contraditória de crise permanente, inclusive no país líder, torna-se forçoso reconhecer os contrapontos desse desenvolvimento. Então, porque temos que copiar também o modelo de desenvolvimento e de turismo dos países ricos? Celso Furtado (1974, p. 75) criticava, desde a década de 1970, este modelo de desenvolvimento dizendo que: "O estilo de vida criado pelo capitalismo industrial tem sido privilégio de uma minoria e a ideia de que os povos pobres possam algum dia desfrutar das formas de vida dos tais povos ricos é simplesmente irrealizável". Para haver desenvolvimento não necessariamente se precisa seguir o modelo dos países ricos industrializados, consumistas.

As teorias conservadoras, da economia clássica de desenvolvimento, adotam a premissa do continuísmo histórico, acreditando que: o subdesenvolvimento é o estádio original ou o ponto de partida para se chegar ao desenvolvimento; é um processo direcional que obedece a fases e etapas; é sinônimo de crescimento econômico e resulta da implementação de tecnologias; que a modernização conduz à urbanização, industrialização e terceirização; os empresários são os agentes principais desse processo e devem ser inovadores e arrojados; as empresas são prioridades, especialmente multinacionais e transnacionais; os obstáculos podem ser diferentes de país a país, mas todos vencíveis; e o Estado não deve intervir no processo de desenvolvimento.

As teorias críticas do desenvolvimento adotam pressupostos do materialismo histórico e se contrapõem aos da teoria conservadora, da economia clássica. Seus fundamentos estão ancorados nas relações sociais de produção, tal como se pode constatar nas seguintes asserções: o desenvolvimento (ou o subdesenvolvimento) faz parte do processo determinado pela relação capital e trabalho, trabalho enquanto meio pelo qual o ser humano se relaciona com os outros seres humanos é produtor da riqueza, é a relação social que determina a relação com a natureza; logo, a relação se dá entre a sociedade-natureza, tanto quanto indivíduo-natureza, a classe dominante cerceia as ideias e falseia a consciência dos dominados e explorados, a exploração é a principal causa da pobreza, o desenvolvimento desigual entre e nações e regiões é a própria 
essência do capitalismo, no mesmo plano da exploração do trabalho pelo capital. Assim, a sociedade que inclui é a mesma que exclui, pois o modelo de desenvolvimento é essencialmente contraditório.

\section{Porque se coloca adjetivos ao desenvolvimento}

O modelo de desenvolvimento adotado no mundo, como no Brasil, foi copiado dos países ricos ocidentais, mas não produziu resultados esperados para toda a sociedade, provocou custos humanos e ambientais muito altos, e alguns, contraditoriamente, difíceis de serem mensurados. Priorizou-se somente a dimensão econômica, tornamonos uma nação rica, mas socialmente uma vergonha nacional. Como avaliar índices de infelicidade, resistências e mesmo de pobreza e fome? Ocorreu um forte processo de crescimento econômico com poucos benefícios sociais, pois concentrou riqueza, desempregou, impactou a natureza, produziu uma modernização dita excludente.

Diagnósticos realizados por organismos como o Programa das Nações Unidas para o Desenvolvimento (PNUD, 1996) revelam que o desenvolvimento apresenta ineficácia de muitas instituições políticas, internacionalização crescente de políticas e falta de controle dos cidadãos sobre estas ações. Tradicionalmente, o autoritarismo dos governos produziu uma sociedade civil frágil, com pouca competência técnica e política para negociar e influenciar políticas públicas.

A falta de ética e de cultura democráticas enfraqueceram os movimentos socais, e, por outro lado, a excessiva tecnificação de controle da vida social conduziu a fragmentação das identidades socioculturais e menor participação popular, favorecendo inúmeras cooptações sociais e comunitárias. Tudo em favor de uma economia mundializada e da predominância do capital financeiro centralizador, objeto deste modelo desenvolvimentista segregador, consumista e injusto. A fragilidade da organização e mobilização das sociedades locais visando interesses locais, somando-se a incapacidade do poder público em defender os interesses nacionais frente ao fortalecimento dos detentores do capital, foi motivo de grandes questionamentos ao modelo de desenvolvimento hegemônico. Tentativas de rompimento passam pela capacidade de produzir utopias, de superar os modelos ideológicos produzindo contrapropostas de desenvolvimento, qualificando-o por adjetivos que foram juntados ao substantivo, mas sem uma mudança substancial.

Se o desenvolvimento tivesse realizado o que está subjacente em seu conteúdo não haveria necessidade de se tentar qualificá-lo acrescentando adjetivos, tais como; endógeno, social, sustentável, para o trânsito, para o turismo, na escala humana, ecodesenvolvimento, dentre muitos outros, denotando uma forma de recuperar o 
conceito, com poucos resultados, pois a questão é estrutural e não conjuntural. O adjetivo social acoplado ao desenvolvimento apareceu consecutivamente em relatórios oficiais como um "complemento meio vago às abordagens econômicas [...] depois como pré-condição ao crescimento econômico e parcialmente como uma justificativa moral para este crescimento e para os sacrifícios que ele pressupunha", tal como foi criticado por Esteva (2000, p. 68).

Quando vários analistas criticam o desenvolvimento pode-se questionar o modelo hegemônico de desenvolvimento. Por exemplo, Esteva (op.cit.) mostrou como a imposição do modelo de desenvolvimento americano impediu que cada país pensasse um modelo endógeno de desenvolvimento, com objetivos diferenciados. $\mathrm{E}$ acrescenta que: Nyerere, ciente da loucura causada pela corrida no encalço de metas estabelecidas de fora da Tanzânia, recomendou mobilização política para atingir objetivos locais. Rodolfo Stavenhagen propôs o etnodesenvolvimento ou o desenvolvimento com autoconfiança, pois se deve "olhar para dentro" e "buscar nossa própria cultura" em detrimento das visões alheias ou emprestadas. Jimoh Omo-Fadaka sugeriu o desenvolvimento "de baixo para cima" e não estratégias "de cima para baixo" por não atingir os objetivos formulados. Orlando Fals-Borda e Anisur Rahman defenderam o desenvolvimento participativo e se fundamentaram nas exclusões feitas em nome do desenvolvimento. Jun Nishikawa indica um "outro" tipo de desenvolvimento para o Japão, ciente do fim da era presente (Esteva, 2000). E Manfred Max-Neff (2012) no Chile, propõe mais recentemente o desenvolvimento na escala humana.

A partir da década de 1970 passou-se a compreender que o desenvolvimento não diz respeito às coisas, mas às pessoas. Sabe-se que esses adjetivos muitas vezes são apenas estratégias políticas, propaganda e marketing da maquilagem verde ou social para vincular imagem positiva aos empreendimentos. Quando se investe nos lugares e nas técnicas, trata-se de progresso e modernização do espaço. Qualquer crescimento que não leve em consideração as necessidades das pessoas não pode ser considerado desenvolvimento. Para Boisier (2003), desenvolvimento se insere como obtenção de contextos, momentos, situações em âmbito que possibilite a potenciação humana para que se transforme em pessoa humana em todas as suas dimensões.

O desenvolvimento implica ainda organização territorial realizada por atores sociais, instituições, sociedades identificadas historicamente e territorialmente realizem ações econômicas, políticas, culturais em modelos de desenvolvimento que aproveite todas as potencialidades locais. É assim que Sachs (1974) concebe o desenvolvimento: equacionando necessidades básicas priorizando fundamentalmente a garantia de acesso à alimentação, vestuário, habitação, serviços públicos, como água potável, 
saneamento, transporte, educação, saúde e lazer. Implica, assim, produção do espaço pelo ser humano, organizando atividades humanas em total respeito à conservação ambiental, para a realização da habitação, do trabalho e do lazer.

No limiar do século XXI emergem experiências em contraponto ao desenvolvimento globalizado, realçando o local, o conhecimento, as organizações cooperativas e participativas, como resistência ao global. Associações e empresas que se pautam em valores diferenciados para a promoção de outro desenvolvimento fundamentado na economia solidária, economia de comunhão e economia criativa, cooperativismo. Assim modelos alternativos de desenvolvimento minam o modelo hegemônico, buscando sustentabilidade econômica associada à socioambiental, com compromisso e postura ética. O desenvolvimento desejado valoriza as pessoas, as culturas, é, portanto na escala humana. O pensador chileno Max Neef (2012) propõe o desenvolvimento a partir da autoindependência das regiões, dos territórios e das pessoas.

\section{Desenvolvimento local e voltado às pessoas}

O desenvolvimento local é aquele realizado em pequenos lugares de forma participativa, levando às mudanças socioestruturais, com caráter endógeno. Nele, os habitantes possuem relativa autonomia, para explorar o potencial do território que beneficie a maioria deles, e decidir como cada um pode contribuir com inovações. São os residentes os agentes principais do desenrolar de todo processo de desenvolvimento e zelam pela qualidade dos relacionamentos interpessoais, interinstitucionais, aproveitam as sinergias em beneficio da coletividade.

Para pensar o desenvolvimento na escala humana, toma-se o pensamento de Max-Neef (2012) como referência para aprofundar e criticar as teorias de desenvolvimento. A escala humana se efetiva com as políticas públicas reorientando suas prioridades para o social e para o indivíduo como beneficiário quando se aprofunda na sociedade a consciência da dignidade do ser humano e quando se extingue a estrutura social que agride sistematicamente os direitos da pessoa humana.

Aprofunda-se a consciência da dignidade do ser humano extinguindo a estrutura social agressora dos direitos humanos. O desenvolvimento privilegiando o ser humano, no desabrochar de suas potencialidades, assegurando aos cidadãos subsistência, trabalho, educação e condições de vida digna. Ao contrário da economia do ter, baseia-se na sociedade do ser, cujo desenvolvimento é centrado no ser humano e na cultura de cooperação e solidariedade (MAX-NEEF, 2012). O respeito e a proteção aos direitos humanos são bases do desenvolvimento e da sociedade humanizada. Afinal, assegura o necessário à vida digna dos cidadãos, com tranquilidade no relacionamento social, 
intercâmbios entre os povos e na construção de bases confiáveis para uma sociedade sustentável. Condições estas consideradas imprescindíveis para a preservação da dignidade humana e para instituir bases sólidas do desenvolvimento do turismo.

Em 1990, a UNESCO, por intermédio da Comissão Econômica para América Latina, sustentou proposta econômica especificando que a educação e o conhecimento conformam o eixo da transformação produtiva com equidade (CORAGGIO, 1996, p. 104), ou seja, um desenvolvimento voltado ao ser humano, que respeita valores, potencialidades e direitos humanos prescinde de investimento em educação. Portanto necessariamente, foge do crescimento econômico puro e simples, exigindo uma visão crítica de desenvolvimento e de sociedade. A sociedade é que precisa ser sustentável, antes de tudo.

A Declaração Universal dos Direitos Humanos, proclamada pela Organização das Nações Unidas, em 1948, que fez 64 anos em 2012 apontou rumos e diretrizes para a promoção do desenvolvimento na escala humana. Defende o direito ao trabalho, ao lazer, a um padrão de vida digno, à instrução, à liberdade e à participação, o direito de ser. Mostra normas jurídicas internacionais, exigências elementares de respeito à pessoa humana e aponta os Estados como responsáveis pela garantia das condições de sua efetivação histórica. A possibilidade de uma política econômica voltada para o desenvolvimento humano exige respeito aos direitos individuais e sociais dos indivíduos, e clareza na definição dos objetivos desse desenvolvimento. Desenvolvimento é um continuum que está sempre dando avanços. Ao voltar-se para a escala humana faz um desses progressos substanciais.

Estudiosos do desenvolvimento na escala humana não têm a pretensão de que esse seja o modelo único, mas têm a convicção de que o padrão consumista não satisfaz a todos e que modelos de desenvolvimento solidários e alternativos poderão servir de contraposição. O modelo hegemônico tem se mostrado incapaz de atingir setores marginalizados e de respeitar os direitos humanos, ou seja, atingir a escala humana. Milton Santos (2000, p.14) mostrou a tendência dessa mudança, dizendo:

Estamos convencidos de que a mudança histórica em perspectiva provirá de um movimento de baixo para cima, tendo como atores principais os países subdesenvolvidos e não os países ricos; os deserdados e os pobres e não os opulentos e outras classes obesas; o indivíduo liberado partícipe das novas massas e não o homem acorrentado; o pensamento livre e não o discurso único.

Voltar o desenvolvimento para a escala humana e o turismo para beneficio de comunidades, ou do desenvolvimento local, significa adotar políticas que criem 
oportunidades de trabalho e renda para a maioria, sem deixar de dar a proteção social requerida, colocando o homem no centro do poder, promovendo sua realização. Concretamente, espera-se que sejam programadas atividades de revalorização do lugar e de crédito aos habitantes do lugar. Atividades planejadas localmente, partindo do social e cultural do grupo para as atividades econômicas, rompendo com a ordem e os valores da sociedade capitalista. As propostas de desenvolvimento na escala humana, para o desenvolvimento social e o turismo de base local mudam o eixo de interesse das ações. Dowbor (1998, p. 81) outro pensador do desenvolvimento social, lembra que:

Não há solução espontânea para esses problemas. Algum tipo de 'mão invisível' institucional capaz de assegurar os equilíbrios. Os atores econômicos e sociais são hoje tão desiguais, que a imagem da 'livre concorrência', capaz de equilibrar os processos de desenvolvimento econômico, é hoje utópica e antiquada... A liberdade sobrevive quando há um mínimo de equilíbrio de poder entre as partes, pois entre desiguais significa liberdade do mais forte e resulta na erosão das instituições. Quando se desarticulam os instrumentos institucionais de governo, ficam mais frágeis os instrumentos políticos de compensação, perdem-se de vista o longo prazo e os interesses humanos.

O desenvolvimento humano sustenta-se na satisfação das necessidades fundamentais, com níveis crescentes de independência dos indivíduos, em articulação orgânica com a natureza, servindo-se da tecnologia, para integrar-se aos processos globais, contudo respeitando os valores e os comportamentos locais.

Os modelos tradicionalmente utilizados para avaliar o desenvolvimento de um lugar baseiam-se em indicadores predominantemente econômicos, como o Produto Interno Bruto (PIB), que não mensura o desenvolvimento. Necessita-se, com efeito, de indicadores do crescimento qualitativo e não apenas de indicadores econômicos, como os índices de realização dos desejos, de educação, de solidariedade, de realização humana, como sujeito/objeto de sua história. Certamente, esses são bastante difíceis de mensurar, até porque o método científico clássico não considera subjetividades. Quanto maior a qualidade de vida das pessoas, maior o processo de desenvolvimento, significando que atingiu a escala humana, satisfazendo necessidades amplas que se alargam pelos desejos, sonhos e utopias.

Mudar a visão do desenvolvimento significa substituir ideias, compromissos, significados assim como mudar indicadores por aqueles mais representativos dessa construção mental remetidos à sociedade e não apenas à economia. O desenvolvimento nacional não pode ser medido apenas pelo PIB (Produto Interno Bruto), que mensura 
apenas a produção material. Deve ser avaliado também sobre a base humana, por isso se vêm procurando medidas socioeconômicas mais realistas.

O Índice de Desenvolvimento Humano (IDH), proposto ainda em 1990 pelo Relatório de Desenvolvimento Humano do PNUD, apresentava grande contribuição metodológica, por incluir outros componentes básicos do desenvolvimento humano, como longevidade, conhecimento ou índice de alfabetização e educação e o padrão de vida. Avaliar o desenvolvimento humano torna-se uma tarefa muito difícil por sua complexidade e dificuldade de mensuração. Para a definição do IDH, o Instituto de Pesquisa Econômica Aplicada (IPEA/CE, 1996) define indicador de longevidade como esperança de vida ao nascer; indicador de nível educacional, a taxa de alfabetização dos adultos e a taxa combinada de matrícula nos ensinos fundamental, médio e superior; indicador de acesso aos recursos, a renda per capita, o poder de compra, baseado no PIB per capita, ajustado ao custo de vida local, traduzida como paridade do poder de compra. A adoção do IDH é um indicador mais fiel, porque sai um pouco do percentual quantitativo, inserindo o qualitativo de uma forma mais abrangente, portanto mais próxima da realidade.

As necessidades humanas são finitas, poucas, classificáveis e as mesmas em toda e qualquer cultura, mudando apenas no tempo e nas culturas as formas e os meios para satisfazer tais necessidades. Essas formas é que determinam a qualidade de vida de um lugar e muitas vezes as formas tradicionais são abandonadas sem participação interna do lugar, por imposição de fora. Segundo Max-Neef (2012) as necessidades humanas são existenciais: ser, ter, fazer, estar; axiológicas: necessidade de subsistência, de proteção, de afeto, de entendimento, de participação, de ócio, de criação, de identidade, e de liberdade. O desenvolvimento pode ser definido conforme o modo como satisfaz tais necessidades. O que está culturalmente determinado não são as necessidades, mas as formas de satisfação dessas necessidades. A necessidade fundamental insatisfeita indica pobreza humana, podendo variar em graus, considerando a carência em afeto, entendimento, participação, ou em bens materiais. A pobreza produz e alimenta patologias individuais e coletivas como angústia, depressão, violência, marginalidade, medo e isolamento.

As pessoas apresentam especificidades por possuírem necessidades próprias que se atêm à própria raiz da natureza humana, por isso chamada necessidades existenciais. São, sobretudo, necessidades de introspecção, amizade, amor, diversão, ou necessidades qualitativas. Outras necessidades se constroem, por isso são necessidades induzidas ou alienadas. Essas são típicas de sociedades identificadas pelo modelo de desenvolvimento: sede de poder, posse, acúmulo quantitativo. Entre as necessidades 
existenciais e as alienadas existe uma profunda diferença, e o modelo de desenvolvimento induz para as alienadas.

O modelo capitalista induz a tantas necessidades externas ao ser humano para que deseje as mercadorias e os serviços como objeto de prazer e de realização da sociedade consumista, com seus desperdícios, segregação e privações. As necessidades básicas diferem das necessidades criadas. Há grupos de populações que não satisfazem sequer o mínimo de suas necessidades básicas, ou se encontram "alienadas", situações que mobilizam a critica dos cientistas sociais.

Em se tratando do lazer e turismo, há lógicas de desenvolvimento de territorialidade e de promoção da atividade segundo paradigmas alternativos, tais como a lógica de Sachs (1986), Sampaio (2005), Coriolano (2003), Morin (1999), voltados aos grupos humanos. Nos quais possuem uma concepção comum de desenvolvimento, aquele voltado para a maioria dos lugares, pessoas, grupos sociais e culturais - o chamado eco-sociodesenvolvimento.

A qualidade da vida humana passa pelo trabalho, mas também pelo lazer e entretenimento. Assim, o lazer o turismo são realizados para elevar o nível de bem estar de visitantes e visitados. Os países cujo desenvolvimento está voltado para a escala humana tornam-se mais preparados à promoção do turismo. Os lugares que não respeitam o direito humano, com desigualdades gritantes, onde há guerra, violência, fome e pobreza[,] inviabilizam o turismo. Nesses lugares, o turismo incomoda e é incomodado.

\section{O significado do desenvolvimento na escala humana e do turismo sustentável}

A ideia de sustentabilidade proposta pela Comissão Mundial do Meio Ambiente e Desenvolvimento da CMMAD/ONU (1987) pauta-se nos princípios de equidade social direito de cada um se inserir no processo de desenvolvimento -, eficiência econômica gestão dos recursos econômicos e financeiros para garantir o funcionamento eficiente da sociedade - e prudência ecológica - a racionalização do consumo, usos de tecnologias limpas, definição de regras para a proteção ambiental.

A Organização Mundial de Turismo (OMT, 2009) define turismo sustentável aquele que na gestão dos recursos atende as necessidades econômicas e estéticas das paisagens, mantendo a integridade cultural, os processos ecológicos essenciais, a diversidade e o sistema de suporte a vida. O conceito de desenvolvimento sustentável 
faz referencia à capacidade de satisfazer as necessidades atuais sem por em perigo a capacidade das gerações futuras para satisfazer suas próprias necessidades

Turismo sustentável é observado em núcleos receptores de turismo, considerando os principais promotores desses serviços, sobretudo na forma como organizam a produção, por exemplo, de forma associativa, em arranjos produtivos locais, controlando o uso efetivo das terras e das atividades econômicas associadas ao turismo. Realiza-se de forma integrada às demais atividades econômicas, com iniciativas que fortalecem a agricultura, a pesca e o artesanato, dentre outras atividades tradicionais.

Nessa linha do desenvolvimento sustentável, a prioridade é pela geração de trabalho para os residentes, focando os empreendimentos com maior poder de impulsionar a economia local, abrindo-se a participação comunitária. Participação assegurada desde o planejamento descentralizado e associativo e mantida com a regulamentação fundiária e a posse da terra de populações indígenas, pesqueiras, das chamadas comunidades nativas. Nos regulamentos das unidades de conservação, ou nos acordos dos comitês de gestão ambiental espera-se compatibilidade com a atividade turística.

A sustentabilidade turística requer planejamento dos usos para minimizar prejuízos ao ambiente e as populações visitadas. O desenvolvimento sendo pautado não apenas no mercado, mas nos valores humanitários, e ambientais. Ações que visam a continuidade da vida, da atividade humana, da capacidade dos animais e das plantas de se reproduzirem ao longo do tempo. Para comunidades de significativas manifestações culturais, o turismo precisa ser controlado para evitar descaracterizações ou impactos, deve ter menor envergadura e cuidados específicos no sentido de assegurar o bem-estar das comunidades (PORTUGUEZ, 2010). Portuguez analisa como o processo ocorre no ["]agroturismo" da região serrana do Espírito Santo, e afirma desenvolvimento socioespacial é um processo de aprimoramento, gradativo de rupturas, bruscas, de melhores condições de vida. Lembra Rezende (2011) em estudos sobre o desenvolvimento pelo Turismo que a China desde o sétimo plano quinquenal (19851990) utiliza efetivamente o turismo como ferramenta para o desenvolvimento e que algumas regiões e províncias, que se decidiram pelo turismo como estratégia de combate a pobreza por serem regiões atrasadas ou comunidades de minorias étnicas, obtiveram sucesso. E que decidir pelo turismo para alavancar o desenvolvimento pode ocorrer de várias maneiras resultando em situações opostas, como se vê nos casos narrados. A experiência da utilização do turismo no enfrentamento da pobreza na China dá conta de que a maneira como a atividade é estruturada localmente teve efeitos diversos no crescimento econômico e no tratamento da pobreza. Diz Rezende que nas províncias chinesas de Yunnan e Guizhou estudadas por Donaldson (2007) aconteceu o 
seguinte. Em ambas províncias pobres seus governantes optaram por desenvolver o turismo de forma diferenciada. Enquanto em Yunnan a opção foi pela "indústria" do turismo, ao contrário em Guizhou, a opção foi por um turismo em pequena escala, de base local. E que ironicamente, a indústria turística de base rural de Yunnan contribuiu para o rápido crescimento econômico da província, de forma concentrada, com pouca contribuição na redução das taxas de pobreza, que permanecem existindo na província. Ao contrário, a comunidade Guizhou que optou pelo turismo em pequena escala, centrada em áreas pobres, embora tenha pouco contribuído para o "desenvolvimento" como ele é comumente entendido, reduziu a pobreza encorajando a participação de pessoas pobres que passaram a empreender e transformar a província.

Sustentabilidade e capitalismo estão sempre em contradição, porém se tratados como pensamento complexo abrem-se caminhos para uma ação dinâmica entre as oposições. Agregar a dimensão planetária, partindo do princípio de que não adianta garantir os direitos humanos, se o planeta continuar em processo de devastação (a questão é que estes direitos humanos não foram garantidos a todos). O grande desafio é a defesa do ser humano, de seu trabalho, de sua dignidade, extinção das desigualdades sociais e a conservação do ambiente onde se vive.

As políticas econômicas passariam a protagonista de ações afirmativas, na proteção das cidades, paisagens, serras, litorais, sertões, enfim, da grande variedade de geossistemas ou espaços geográficos. Com programas que criem políticas voltadas à diminuição das desigualdades regionais, disparidades sociais, à conservação ambiental, à manutenção de lugares saudáveis. Um novo paradigma para o desenvolvimento que torne a sociedade mais justa e solidária; que repensem as práticas do consumo; aumente a consciência ecológica, a cidadania e a educação ambiental.

\section{Referências Bibliográficas}

BAUMAN, Zigmunt (2010) Capitalismo Parasitário. Rio de Janeiro: Zahar.

BOISIER, Sérgio (2003) El desarrollo em sul lugar. Série Geolibros. Inst, de Geografia. Cidade: Pontificia Universidad Catolica di Chile.

CHESNAIS, François. (1996) A Mundialização do capital. São Paulo: Editora Xanã.

CMMAD/ONU (1987) Our Common Future. Oxford: Oxford University Press

CORAGGIO, J. Luis (1996) Desenvolvimento Humano e Educação. São Paulo: Cortez

CORIOLANO, Luzia Neide (2003) "Os limites do Desenvolvimento e do Turismo". In:

Luzia Neide Coriolano (ed.) O Turismo de Inclusão e o Desenvolvimento Local. Fortaleza: FUNECE. 
DONALDSON, J (2007) Tourism, Development and Poverty Reduction in Guizhou and Yunnan. The China Quarterly, V. 190, June 2007, p 333-351.

DOWBOR, Ladislau (1998) A Reprodução Social: Proposta para uma gestão descentralizada. Petrópolis: Vozes.

ESTEVA, Gustavo (2000) "Desenvolvimento". In: W. Sachs (ed.) Dicionário do Desenvolvimento. Petrópolis: Vozes, 2000.

FURTADO, Celso (1974) O Mito do Desenvolvimento Econômico. Rio de Janeiro: Paz e Terra.

IPEA (1996) Relatório sobre o Desenvolvimento Humano. Rio de Janeiro: IPEA/CE.

MAX-NEEF, Manfred (2012) Desenvolvimento à Escala Humana: ConcepçãoAplicação-Reflexos Posteriores. Blumenau: EDFURB

MORIN, Edgar (1999) Ciência com Consciência. Rio de Janeiro: Bertrand Brasil.

ORGANIZAÇÃO MUNDIAL DE TURISMO - OMT (2009) Tendências do Turismo Internacional: O mundo e as Américas. Madrid: Conselho Executivo da OMT

PNUD - Programa das Nações Unidas para o Desenvolvimento (1996) Human Development Report. Chile: PNUD.

PORTUGUEZ, Anderson (2010) Geografía humana del bajo rio Doce. Uberlândia: Assis.

REZENDE, Ricardo (2011) Turismo de Base Comunitária, Política Pública e Efeitos Sobre O Local: O caso do projeto "Um Vale Verde de Verdade”, Pirenópolis (GO). Dissertação. Escola Nacional De Ciências Estatísticas - ENCE.

SACHS, Ignacy (1986) Ecodesenvolvimento, Crescer sem Destruir. São Paulo: Vértice .

SACHS, Ignacy (1974) Environnement et styles de développement. In Economies, Sociétis, Civilizations $n .{ }^{\circ} 3$. Paris: Ehess.

SAMPAIO, Carlos (2005) Turismo como fenômeno Humano: princípios para se pensar a sócio economia. Santa Cruz do Sul: EDUNISC.

SANTOS, Milton (2000) Por uma outra Globalização. Do pensamento único à consciência universal. Rio de Janeiro: Record. 
Luzia Neide Coriolano é Doutorada em Geografia, Professora do PROPGEO, Coordenadora do Grupo de Pesquisa Turismo, Território e Cultura e Coordenadora Adjunta do Mestrado Profissional em Gestão de Negócios Turísticos / Universidade Estadual do Ceará (UECE/Brasil). É pesquisadora do CNPq..

luzianeidecoriolano@gmail.com 